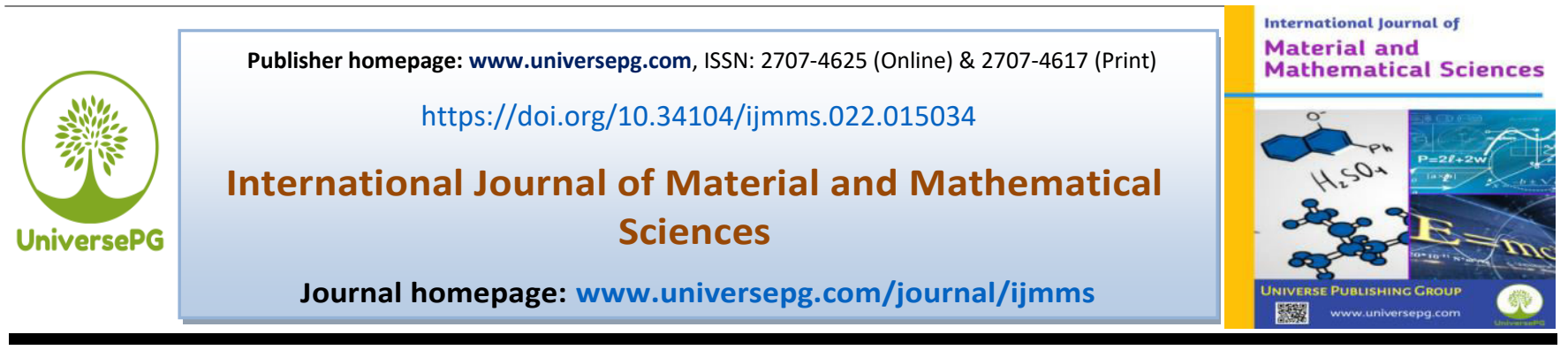

\title{
Solution of Large-Scale Linear Programming Problem by Using Computer Technique
}

\author{
Shohal Hossain ${ }^{1}$, Shamima Aktar ${ }^{2}$, and Samme Akter Mithy ${ }^{3}$ \\ ${ }^{1}$ Center for Multidisciplinary Research, Gono Bishwabidyalay, Savar, Dhaka-1344, Bangladesh; ${ }^{2}$ Supporting Department \\ (Economics), Gono Bishwabidyalay, Savar, Dhaka-1344, Bangladesh; ${ }^{3}$ Research Monitoring and Evolution Division, Gono \\ Shasthaya Kendra, Savar, Dhaka-1344, Bangladesh. \\ *Correspondence: sohe16944@gmail.com (Shohal Hossain, Research Assistant, Center for Multidisciplinary Research, Gono \\ Bishwabidyalay, Savar, Dhaka-1344, Bangladesh).
}

\begin{abstract}
Linear programming (LP) is an important part of applied mathematics. This method has found its applications to important areas of product mix, blending and diet problems. Steel, chemical, food processing industries and Oil refineries industry are also using LP with considerable success. But in practical LP can be very large. In this paper, our intent is to formulate an LP model of some large-scale real-life-oriented problems and to apply computer techniques for solving these problems. Starting with the graphical procedure which provides an ample amount of understanding into some fundamental concepts, the simple procedure of solving LP problems is developed. Finally, a special class of LP problem, namely Transportation is taken up and solved. We also solved the simplex system by using FORTRAN programming.
\end{abstract}

Keywords: Linear programming, Large-scale LP, Linear optimization models, and FORTRAN program.

\section{INTRODUCTION:}

Linear programming (LP) is also called linear optimization it's applies to optimization models inside of which the objective and constraint functions are strictly linear. The technique are used in large range of applications, including food and agriculture, different type of industry, transportation, economics, health care systems, military, behavioral sciences and the social sciences, etc. It also boasts efficient computation algorithms for problems with a great constraints and variables.

Actually, by reason of its tremendous computation efficiency, LP forms the spine of the solution algorithms for operations research model, including with stochastic, integer and non-linear programming. In this paper, our intent is to formulate LP problem of a sizeUniversePG I www.universepg.com able large-scale real life oriented problems and to develop FORTRAN computer program for solving it and analyses the solution of the problem. To do this we have to talk about the following prerequisites.

\section{Programming problem}

Programming problem is said to efficient and easy to use of little resources. By resources, we have a tendency to mean personnel material, machine, land and capital, and so on. These problems are extremely useful nowadays because of their applicability to real-world problems in industry, government offices, military management, and business establishments. Programming problem is sometimes dubbed as optimization problems. In a number of problems, we would like to attenuate or maximize a numerical function subject to certain constraints or restrict- 
tions. There are many classical systems are available to solve such problems. But they're not enough, as more and sophisticated problems arise. Hence new methods are being developed from time to time. The type of programming problems can be separated into two sub-classes: $1^{\text {st }} \mathrm{LP}$ and $2^{\text {nd }}$ nonLP problems. In this paper, we shall discuss the linear programming problem in detail. In applied mathematics, the target function and constraints are all linear expressions in some unknown variables. The great mathematician G. B. Dantzig formulated the general linear programming problem and devised the most popular simplex method for solving such problems in 1947. Scientists have been using this method since 1951.

\section{Basic form of mathematical programming problem}

The Basic form of mathematical programming problem from Rao, (2005) is given below:

Optimize $Z=f(X)$

Subject to $g_{i}(X) \leq 0, i=1,2, \ldots \ldots \ldots, m$

$\mathrm{X} \geq 0$

Where, $f(X)$ and $g(X)$ can be taken to be general functions if the vector $X=\left(x_{1}, x_{2}, x_{3}, \ldots \ldots, x_{n}\right) \varepsilon R^{n}$. Frequently these functions are taken to be continuous or continuously differentiable. Thus we will have to find a column vector $X$ which optimizes (minimizes or maximizes) the objective or targeted function $f(X)$ subject to the $\mathrm{m}$ constraints -

$\mathrm{g}_{\mathrm{i}}(\mathrm{X}) \leq 0, \mathrm{i}=1,2, \ldots \ldots \ldots, \mathrm{m}$.

In the function $\mathrm{f}$ and all $\mathrm{g}_{\mathrm{i}}$ are linear functions of $\mathrm{X}$, then the problem is called to linear programming. Yet, if any one of these functions is non-linear, then it is said a non-linear programming problem. For our purpose we'll stick on to a maximizing problem. Note that $\operatorname{minf}(\mathrm{X})=-\max (-\mathrm{f}(\mathrm{X}))$. Therefore minimize problem can be change to a maximizing problem. If we run into equality constraints like $h(X)=0$, it can be changed to a set inequalities: $h(X) \leq 0$, and $h(X) \geq 0$. This is turn is equal to a pair of constraints like $h(X) \leq 0$ and $-h(X) \geq 0$. Hence, with none loss of generality, we will write the mathematical programming problem as follows:

maximizeZ $=f(X)$

Subjecttog $_{\mathrm{i}}(\mathrm{X}) \leq 0, \mathrm{i}=1,2, \ldots \ldots \ldots, \mathrm{m}$

$\mathrm{X} \geq 0$.

UniversePG I www.universepg.com
General form of linear programming Problem (LPP)

A LP problem is abbreviated by LPP mathematically; a general LPP can be stated as follows:

OptimizeZ $=c_{1} x_{1}+c_{2} x_{2}+\cdots \ldots \ldots \ldots c_{n} x_{n}$ ，

Subject to the conditions

$a_{11} x_{1}+a_{12} x_{2}+\cdots+a_{1 j} x_{j}+\cdots+a_{1 n} x_{n}(\leq,=, \geq) b_{1}$

$a_{21} x_{1}+a_{22} x_{2}+\cdots+a_{2 j} x_{j}+\cdots+a_{2 n} x_{n}(\leq,=, \geq) b_{2}$

$::::$

$a_{i 1} x_{1}+a_{i 2} x_{2}+\cdots+a_{i j} x_{j}+\cdots+a_{i n} x_{n}(\leq,=, \geq) b_{i}$

$::::$

$a_{m 1} x_{1}+a_{m 2} x_{2}+\cdots+a_{m j} x_{j}+\cdots+a_{m n} x_{n}(\leq,=, \geq) b_{m}$

And non-negativity restrictions $x_{j} \geq 0, j=1,2, \ldots \ldots \ldots n$.

Here in the set of conditions we have written $(\leq,=$ ,$\geq$ ) which means that any of the three signs may be there. Also optimize means either maximize or minimize. The linear function which is to be optimized called the target function. The conditions are referred as constraints. Any problem which can be formulated in the in excess of form is called a L.P.P. By finding a solution to (1.3) we mean to find the non-negative values of variables $x_{1}+x_{2}+\cdots+x_{n}$ which optimize Zand assure all the constraints.

\section{The Standard form of LP problem}

The characteristics of standard form are as follows as -

1) All constraints are equations apart from the nonnegativity restrictions that stay inequalities.

2) The right-hand side element of each constraints equation is non-negativity.

3) All variables are non-negativity.

4) The targeted of the maximization or the minimization type.

\section{METHOLODOGY:}

One of the main point of LP is recognize a problem which can be handed by LP and then to formulate the mathematical model of it. The most steps to represent a linear program in symbols are as follows:

Step1. Establish the unknown decision variables to be determined and assign symbol to them.

Step2. Establish all the restrictions in the problem and show them as linear equations.

Step3. Establish the objective or aim and represent it as a linear function of selection variables.

The procedures are going to be clearer by the subsequent examples. Formulation of models is not any science but an art, which can be more refined to you by practice. 


\section{Requirements for formulating a Linear Problem}

There are six basic necessary requirements for the formulation of a linear programming problem (LPP) -

1) Well defined linear impartial function. A linear impartial function should be clearly defined mathematically.

2) Alternative courses of action. There should be different courses of action so that a problem of choosing best may arise.

3) The limitation is obliged to effective of being expressed mathematically in the form of linear equation or inequalities.

4) Linear constraint must be expressed mathematiccally. The constraints have to be effective of being expressed mathematically in the form of linear equation or inequalities.

5) Variables in the problem have to be interrelated, so that it can be possible to formulate mathematical relationship among them.

6) Resources must be limited i.e. they must be finite and economically quantifiable.

\section{Uses of LP in Business and industry}

We can use the advantage of LP problem in the section of business and industry. Now we discuss some uses of LPP in the above section. Linear programming may be applied to many fields of study. It is used most extensively in business and economics, but also can be utilized for a few engineering problems. Industries use linear programming (LP) models including manufacturing, telecommunications, transportation, and energy. It has proved useful in modeling diverse sorts of problems in planning, routing, scheduling, assignment, and design/style. Metal working industries use linear programming (LP) for shop loading and for determining the section between producing and buying a selected or specific part. Paper and textile industries have used LP to define the optimal cutting method in order to minimize trim losses. LP has also been used in determining the best route for aircrafts and ships. Another uses of LP is in the food processing industry that is to establish the optimal mix of feeds, optimal allocation of crates from various plants to different ware houses etc. LP has also been used in establishing the best route for aircrafts and ships. Application of LP has also been made within the service industries. Accounting firms use it for asset valuation and for assigning auditors to tasks in an optimal way. Financial institutions and firms have used LP for evaluating investment plans, for the choice of Bond or Mutual Funds' Portfolios, for Capital budgeting and for longrange financial planning, etc. Similarly, in advertising media, LP has been employed for assigning advertising dollars to different media plans. Thus we see that we will the LPP within the various sections of business and industry. So its crucial method and its applications are in worldwide (Niazai et al., 2021; Sami et al., 2021).

\section{Some example of applications of linear program- ming technique}

Major areas of the application of LP technique are as mentioned below:

1) Production planning

2) Feed mix and Transportation

3) Stock cutting or slitting

4) Water quality management

5) Oil drilling and production

6) Rally line balancing

7) Advertising media selection

8) Site location \& Applications in agriculture

9) Assignment of jobs.

\section{FORTRAN computer program for linear program- ming}

Although very small LP models are often solved with simply a pencil and paper, by methods described in any textbook; this would never be done for practical problems, the amount of calculation involved in solved in solving a realistic model always necessitates the use of a computer. Practical LP models can be very large. Most models have a few hundred limitations and variables and solve a matter of minutes on most computers sizeable number of large models involving thousands of limitations and variables have also been built. With this model the solution times are usually measured in hours. There also exist a few models with hundreds of limitations and variables. Such models can take days to solve on a computer. The largest liner programming model reported to date has a hundred thousand limitations. For a LP model the number of limitations is a fairly good indicator of its computational difficulty. As a very rough rule of thumb he time to solve liner programs model increase as the cube of the number of limitations. By doubling the number of limitations one would therefore expect to 
multiply the solution time by eight. There is clearly great virtue in organizing a mathematical programming calculation as efficiently as possible on a computer. One of the major characteristics of practical model which is exploited in the calculations in sparsely. If one examines the coefficients in a realistic sized model one will almost always find that the great majority of them are zero. For a thousand limitations model, for example, one would probably only find that about $1 \%$ of the coefficients were non-zero. The dominant feature of sparsely in practical models is often overlooked when mathematical programming is studied theoretically through small-contrived examples. Computer programs which we solve practical mathematical programming models almost always make use of sparsely.

\section{Mathematical Formation and Graphical Repre- sentation of LPP}

\section{Graphical Procedure}

The graphical ways for determination LPP are predicated on a well-defined set of logical steps. Following this systematic procedure, the given LP problems is often solved with a lowest amount of computational effort. We shall explain the procedure by taking a simple problem given below

\section{Working procedure}

Working procedure to solve a LPP graphically from Grewal, (1998) is given bellow:

Step 1: Construct the given problem as a LPP.

Step 2: Plot of the specified limitations as equalities on $\mathrm{x}_{1}-\mathrm{x}_{2}$ co-ordinate plane and determined the convex region formed by them.

Step 3: Determine the vertices of the convex region and find the worth of the objective or aimed function at each vertex. The vertex provides the prime value of the objective function gives the specified prime solution to the problem. Otherwise: Draw the dotted line through the origin representing the targeted function with $\mathrm{Z}=$ 0 . As $\mathrm{Z}$ is increased from zero, this line moves to the right remaining parallel to itself. We continue sliding this line till it's farthest far away from the origin and passes through just one vertex of the convex region. This is the vertex where the utmost highest value of $\mathrm{Z}$ is attained. When it's required to attenuate $\mathrm{Z}$, value of $\mathrm{Z}$ is increased till the line passes through the closest vertex of the convex region. The drawback of this UniversePG I www.universepg.com method is that the problem of higher dimensionality can't be solved by this method. A problem of three dimensions can also be handled by this method but it is complicated enough.

\section{Limitations of the graphical procedure}

As mentioned before this system can be applied to problems involving only two variables while the lion's share of the practical situations do involved over than two variables. Therefore it is not a heavy tool of LP. But the method is really useful to explain LP technique to the persons who are not familiar with this. It is easy to understand even to school students. In a class room, this system can be used as a first sight method to explain "how to solve a LPP". The various consequences of the optimal solutions and the simplex system can be demonstrated with the help of graphical method.

\section{Some real life linear programming problems}

By using Mathematica from Don, (2004) we can solved any LP problem with two or three variables and draw a physical picture. Some practical problem is showed below.

\section{Production Problem}

Hasim food limited company produced two different types of Seejan juices (250ml pack and $200 \mathrm{ml}$ pack). Each unit of $250 \mathrm{ml}$ pack has 36 pices and each unit of $200 \mathrm{ml}$ pack has 48 pieces. The company builds profit of 3tk and 2tkeach unit of products of $250 \mathrm{ml}$ and $200 \mathrm{ml}$ pack respectively. The products are produced in a common production process and are sold in two separate markets. Machine works 20 hours in a day. It takes 1 minute to produce 72 pieces of $250 \mathrm{ml}$ pack and takes 1 minute to produce 144 pieces of $200 \mathrm{ml}$ pack. The market has been surveyed and company officially feels that the highest number of unit's $250 \mathrm{ml}$ pack that can be sold is 2300 and the highest number of unit's $200 \mathrm{ml}$ pack is 3000 units. Subject to these limitations the products can be cold in any convex combination. We formulate the overhead problem as a LP problem and solve it graphically by using mathematica.

\section{Solution}

Formulation of LP problem of the problem:

Let $\mathrm{x}_{1}$ and $\mathrm{x}_{2}$ be the number of unit of product $250 \mathrm{ml}$ pack and $200 \mathrm{ml}$ pack respectively. 


\section{Objective function}

The company makes profit of $3 \mathrm{tk}$ and $2 \mathrm{tk}$ per pieces of products of $250 \mathrm{ml}$ pack and $200 \mathrm{ml}$ pack respectively and each unit of $250 \mathrm{ml}$ pack has 36 pices and each unit of $200 \mathrm{ml}$ pack has 48 pieces.

So the overall profit -

Maximize $\mathrm{Z}=3 \times 36 \mathrm{x}_{1}+2 \times 48 \mathrm{x}_{2}$

\section{Subject to the constraints}

It takes 1 minute to produce 72 pieces of $250 \mathrm{ml}$ pack and takes 1 minute to produce 144 pieces of $200 \mathrm{ml}$ pack. So it takes $36 / 72$ or $1 / 2$ minute to produce 1 unit of $250 \mathrm{ml}$ pack and takes $48 / 144$ or $1 / 3$ minute to produce 1 unit of $200 \mathrm{ml}$ pack.

So that -

$1 / 2 x_{1}+1 / 3 x_{2} \leq 20 \times 60$

or, $1 / 2 x_{1}+1 / 3 x_{2} \leq 1200$

And the highest number of unit's $250 \mathrm{ml}$ pack that can be sold is 2300 and the highest number of unit's $200 \mathrm{ml}$ pack is 3000 units.

So that -

$\mathrm{x}_{1} \leq 2300$

And $x_{2} \leq 3000$

So the LP model as

Maximize $\mathrm{Z}=3 \times 36 \mathrm{x}_{1}+2 \times 48 \mathrm{x}_{2}$

Subject to $1 / 2 x_{1}+1 / 3 x_{2} \leq 1200$

$\mathrm{x}_{1} \leq 2300$

$\mathrm{x}_{2} \leq 3000$

Where, $\quad x_{1} \geq 0 \& x_{2} \geq 0$

\section{Solution by mathematica}

\section{Input}

Maximize $\left[\left\{108 \mathrm{x}_{1}+96 \mathrm{x}_{2},\left\{\left(\frac{1}{2}\right) \mathrm{x}_{1}+\left(\frac{1}{3}\right) \mathrm{x}_{2} \leq 1200\right.\right.\right.$,

$\left.\left.\left.\mathrm{x}_{1} \leq 2300, \mathrm{x}_{2} \leq 3000, \mathrm{x}_{1} \geq 0, \mathrm{x}_{2} \geq 0\right\}\right\},\left\{\mathrm{x}_{1}, \mathrm{x}_{2}\right\}\right]$

\section{Output}

$\left\{331200,\left\{\mathrm{x}_{1} \rightarrow 400, \mathrm{x}_{2} \rightarrow 3000\right\}\right\}$

\section{Input}

$$
\begin{gathered}
\operatorname{RegionPlot}\left[\left\{\left(\frac{1}{2}\right) \mathrm{x}_{1}+\left(\frac{1}{3}\right) \mathrm{x}_{2} \leq 1200, \mathrm{x}_{1} \leq 2300, \mathrm{x}_{2}\right.\right. \\
\left.\leq 3000, \mathrm{x}_{1} \geq 0, \mathrm{x}_{2} \geq 0\right\}, \\
\left.\left\{\mathrm{x}_{1},-1000,4000\right\},\left\{\mathrm{x}_{2},-1000,4000\right\}\right]
\end{gathered}
$$

\section{Output}

The prime solution is the intersection of the two line $1 / 2 x_{1}+1 / 3 x_{2} \leq 1200 \& x_{2} \leq 3000$ which yields $\mathrm{x}_{1}=400 \& \mathrm{x}_{2}=3000$ the associated minimum value of the feed mix is -

$$
\begin{aligned}
& Z=108 \times 400+96 \times 3000 \\
& =331200 \mathrm{tk}
\end{aligned}
$$

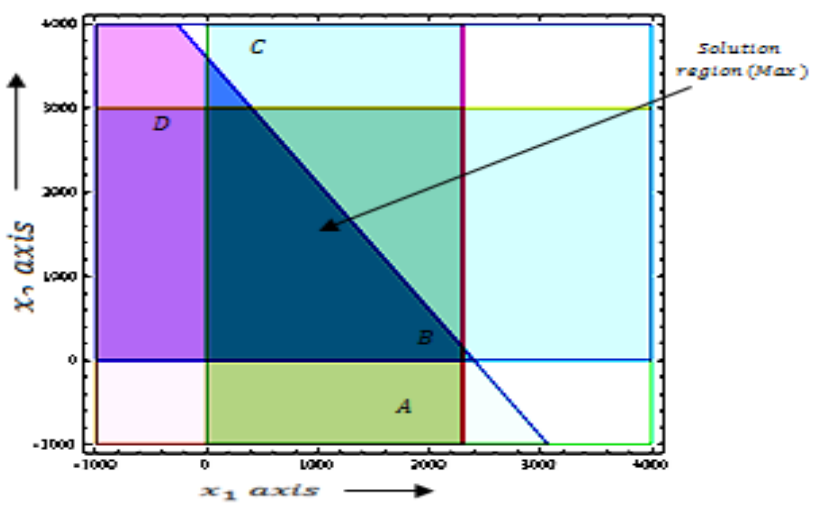

Fig. 1: Feasible Region of the example.

\section{Problem 2.2 (Diet Problem)}

Zakir Farms uses at least $800 \mathrm{lb}$ of particular feed daily. The particular feed is a mixture of corn and soybean flour meal with the following compositions Taha, (2003):

Table 1: $\mathrm{lb}$ per $\mathrm{lb}$ feedstuff.

\begin{tabular}{|c|c|c|c|}
\hline Feedstuff & Protine & Fiber & Cost(tk/lb) \\
\hline Corn & .09 & .02 & .30 \\
\hline Soybean flour & .60 & .06 & .90 \\
\hline
\end{tabular}

The dietary requirements of the particular feed are minimum $30 \%$ protein and at most 5\% fiber. Zakir Farms wishes to work out the daily minimum-cost feed mix.

\section{Solution}

Because the feed mix consists of corn and soybean flour meal, the choice variables are defined as:

$\mathrm{x}_{1}=\mathrm{lb}$ of corn within the daily mix

$\mathrm{x}_{2}=\mathrm{lb}$ of Soybean flour meal within the daily mix

The targeted function seeks to shorten the total every day price of the feed mix and is thus indicate as Minimize $\mathrm{Z}=.3 \mathrm{x}_{1}+.9 \mathrm{x}_{2}$

The obstruction of the model reflect the per day amount needed and therefore the dietary demand. Because Zakir Farms needs at minimum $800 \mathrm{lb}$ of feed each day, the related constraint are often expressed as $\mathrm{x}_{1}+\mathrm{x}_{2} \geq 800$

As for the protein dietary demand constraint, the amount of protein take in $\mathrm{x}_{1} \mathrm{lb}$ of corn and $\mathrm{x}_{2} \mathrm{lb}$ of soybean flour meal is $\left(.09 \mathrm{x}_{1}+.6 \mathrm{x}_{2}\right)$ lb. This quantity 
must equal a lowest of $30 \%$ of the total feed mix $\left(\mathrm{x}_{1}+\right.$ $\left.\mathrm{x}_{2}\right)$ lb; that's

$.09 \mathrm{x}_{1}+.6 \mathrm{x}_{2} \geq .3\left(\mathrm{x}_{1}+\mathrm{x}_{2}\right)$

In the same manner, the fiber constraint is made as

$.02 \mathrm{x}_{1}+.06 \mathrm{x}_{2} \leq .05\left(\mathrm{x}_{1}+\mathrm{x}_{2}\right)$

The constraints are clarify by grouping all the terms in $\mathrm{x}_{1}$ and $\mathrm{x}_{2}$ and moving them to the left side inequality, leaving only a constant on the right-hand side. The complete model will becomes -

Minimize $\mathrm{Z}=.3 \mathrm{x}_{1}+.9 \mathrm{x}_{2}$

subject to $\mathrm{x}_{1}+\mathrm{x}_{2} \geq 800$

$.21 \mathrm{x}_{1}-.30 \mathrm{x}_{2} \leq 0$

$.03 \mathrm{x}_{1}-.01 \mathrm{x}_{2} \geq 0$

Where, $x_{1}, x_{2} \geq 0$

\section{Solution by mathematica}

\section{Input}

Minimize $\left[\left\{.3 \mathrm{x}_{1}+.9 \mathrm{x}_{2},\left\{\mathrm{x}_{1}+\mathrm{x}_{2} \geq 800, .21 \mathrm{x}_{1}-.30 \mathrm{x}_{2}\right.\right.\right.$ $\leq 0$,

$\left.\left.\left..03 \mathrm{x}_{1}-.01 \mathrm{x}_{2} \geq 0, \mathrm{x}_{1} \geq 0, \mathrm{x}_{2} \geq 0\right\}\right\},\left\{\mathrm{x}_{-} 1, \mathrm{x}_{-} 2\right\}\right)$

\section{Output}

$\left\{437.647,\left\{\mathrm{x}_{1} \rightarrow 1470.588, \mathrm{x}_{2} \rightarrow 329.412\right\}\right\}$

\section{Input}

Region Plot $\left[\left\{\mathrm{x}_{1}+\mathrm{x}_{2} \geq 800, .21 \mathrm{x}_{1}-.30 \mathrm{x}_{2}\right.\right.$ $\leq 0, .03 \mathrm{x}_{1}-.01 \mathrm{x}_{2} \geq 0$

$\left.\left.\mathrm{x}_{1} \geq 0, \mathrm{x}_{2} \geq 0\right\},\left\{\mathrm{x}_{1},-500,2000\right\},\left\{\mathrm{x}_{2},-500,2000\right\}\right]$

\section{Output}

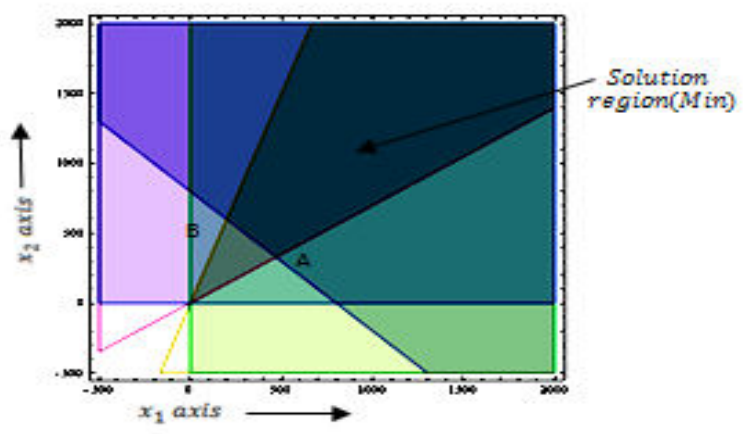

Fig. 2: Feasible Region of the example.

The optimal solution is the joining of the two line $\mathrm{x}_{1}+$ $\mathrm{x}_{2} \geq 800 \& .21 \mathrm{x}_{1}-.30 \mathrm{x}_{2} \leq 0$ which yields $\mathrm{x}_{1}=$ $470.588 \mathrm{lb} \& \mathrm{x}_{2}=329.412 \mathrm{lb}$. The associated minimum value of the feed mix is -

$\mathrm{Z}=.3 \times 470.588+.9 \times 329.412$

$=437.647 \mathrm{tk}$ per day

\section{Simple Method with computer Programming for Solving LPP}

Simplex system is the most popular process to solve the general linear programming problem. George B. UniversePG I www.universepg.com
Dentzing in the year 1947 formulated the general LPP and devised the simplex system for solving these LPP. In 1979, Khachiyan devised the ellipsoid method. More recently, in 1984 N Karmarkar developed a new system to solved LPP. For large problems the system provides solution faster than the previous system. We want to discuss the simplex system in detail and develop FORTRAN computer program for solving problem.

\section{Simplex System}

In the previews, we have to formulate the general LP problem which is developed by Rao, (2005). Our aim is to find an n-component vector $X=\left(x_{1}, x_{2}, \ldots x_{n}\right)^{T}$ which optimizes the linear objective function $Z=C X$ subject to the constraints $A X=b$ and $X \geq 0$. Here $A$ is a $m \times n$ matrix where $m<n$. If $m=n$, a unique solution of the process $A X=b$ is obtained provided the matrix $A$ is non-singular. This is not of interest because no option is left to find an improved solution. But if $m<n$ a number of solutions can be start so that the simplex process will be select the top solution. This is clear if we see the definition of the basic solution defined in chapter 3. By assigning different value to $n-m$ variables instead of zero value we get a number of solutions.

The case $m>n$ is similar to the one with $m-n$. In this case also we get a unique solution provided the system of equations $A X=b$ is consistent.

We rewrite the general LP problem -

Maximize $\mathrm{Z}=\mathrm{CX}$

subject to $\mathrm{AX}=\mathrm{b}$

$\mathrm{x} \geq 0$

\section{Working procedure of the simple method}

Assuming the existence of a beginning basic feasible solution, and prime solution to any LPP by simplex system is found from Grewal, (1998) as follows:

Step 1. (i) Check whether the target function is to be maximized or minimize

If $\mathrm{Z}=\mathrm{c}_{1} \mathrm{x}_{1}+\mathrm{c}_{2} \mathrm{x}_{2}+\mathrm{c}_{3} \mathrm{x}_{3}+\cdots+\mathrm{c}_{\mathrm{n}} \mathrm{x}_{\mathrm{n}}$ is to be decreased, then convert it into a problem of maximization, by writing -

Minimize Z = Maximize $(-\mathrm{Z})$

(ii) Check whether all b's are non-negative.

If any of the $b_{i}^{\prime} s$ is negative, multiply each side of that constraint by -1 so on make its right hand side positive. 
Step 2. Express the issue within the standard form. Convert all inequalities of constraints into equations by introducing slack/surplus variables within the constraints giving equations of the form -

$a_{11} x_{1}+a_{12} x_{2}+a_{13} x_{3}+\cdots+s_{1}+0 s_{2}+0 s_{3}+\cdots=b_{1}$

Step 3. Find an initial basic feasible solution.

If there are $m$ equations involving $n$ unknowns, then assign zero values to any $(n-m)$ of the variables for finding a solution. Starting with a basic solution for which $x_{j}: j=1,2, \ldots,(n-m)$ are each zero, find all $s_{i}$. If all $s_{i}$ are $\geq 0$, the basic solution is feasible and non-degenerate. If one or more of the $s_{i}$ values are zero, then the solution is degenerate.

Table 2: The above information is conveniently expressed in the following simplex.

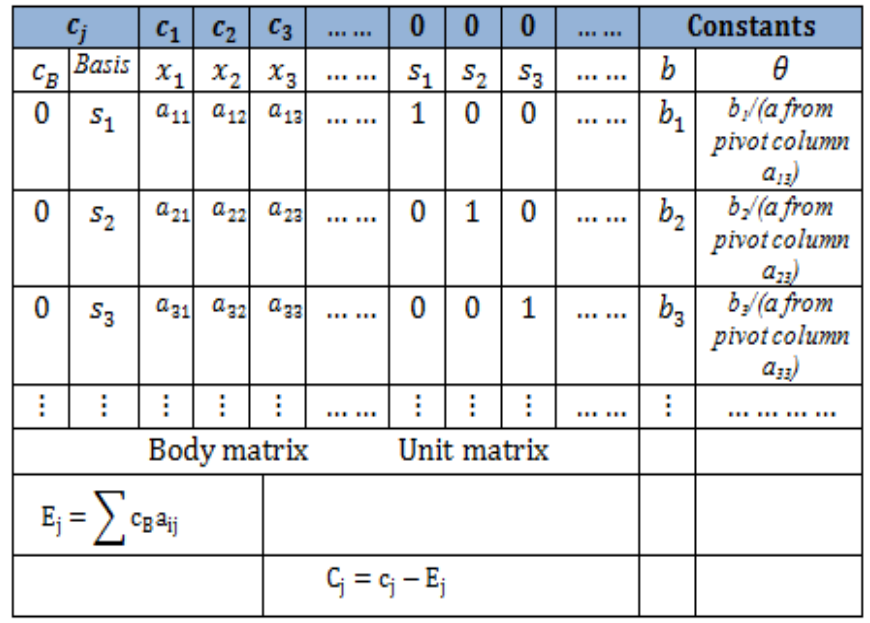

Here, $s_{1}, s_{2}, s_{3}$, etc. are said to basic variables and $x_{1}, x_{2}, x_{3}$ etc. are said to non-basic variables. Basis refers to the basic variables $s_{1}, s_{2}, s_{3} \ldots \ldots c_{j}$ row indicates the coefficients of the variables in the targeted function; while $c_{B}$-column indicates the basic variables only in the targeted function. $b$-column indicates the values of the basic variables while remaining variables will always be zero. The coefficients of $x^{\prime} s$ in the constraint equations constitute the body matrix while coefficients of slack variables constitute the unit matrix.

Step 4. Apply optimality test.

Compute $C_{j}=c_{j}-Z_{j}$ where $Z_{j}=\sum c_{B} a_{i j}$

$C_{j}$-row is called net evaluation row and denotes the per unit increases in the targeted function if the variable heading the column is bought into the solution. If all $C_{j}$ UniversePG I www.universepg.com are non-positive, then the primary general feasible solution is prime. If even one $C_{j}$ is non-negative, then the running feasible solution is not prime and proceeds to the next step.

Step 5. (i) Identify the incoming \& outgoing variables. If there are more than one positive $C_{j}$, then the incoming variable is the one that heads the column containing maximum $C_{j}$. The column containing it's referred to as the lead column which is shown marked with an arrow at rock bottom. If more than one variable has the same maximum, $C_{j}$ any of these variables may be selected arbitrarily as the incoming variable. Now divide the elements under $b$-column by the corresponding elements of key column and choose the row containing the lowest nonnegative ratio $\theta$. Then replace the corresponding basic variable. It is named as the outing variable. The corresponding row is termed the main row which is expressed marked with an arrow on its right end. The element at the intersection of the main row and key column is named the main element which is expressed bracketed. If all these ratios are $\leq 0$, the incoming variable may be made as bigger as we please without violating the feasibility condition. Hence the matter problem has a borderless solution and no additional iteration is required.

(ii) Iterate towards an optimal solution.

Drop the outgoing variable and introduce the incoming variable together with its related value under $c_{B}$ column. Convert the main element to unity by diverge the main row by the main element. Then make all other elements of the main column 0 (zero) by subtracting proper multiples of main row from the opposite rows.

Step 6. Goto step 4 and repeat the computational procedure up to either an unbounded solution is obtained.

In this paper we like to discuss two-phase simplex method which is given below.

\section{Two phase method}

After adding non-natural variables to the constraints of the LP problem we can find a pair of $m$ unit vectors which constitute the primary basis. In phase-I we try to find one general feasible solution to the authentic or 
real problem, if one exists in Phase-II either the prime solution is found out or we come to the conclusion that no finite optimum solution exists.

\section{Flow Chart}

\section{Simplex Algorithm for Maximization LPP}

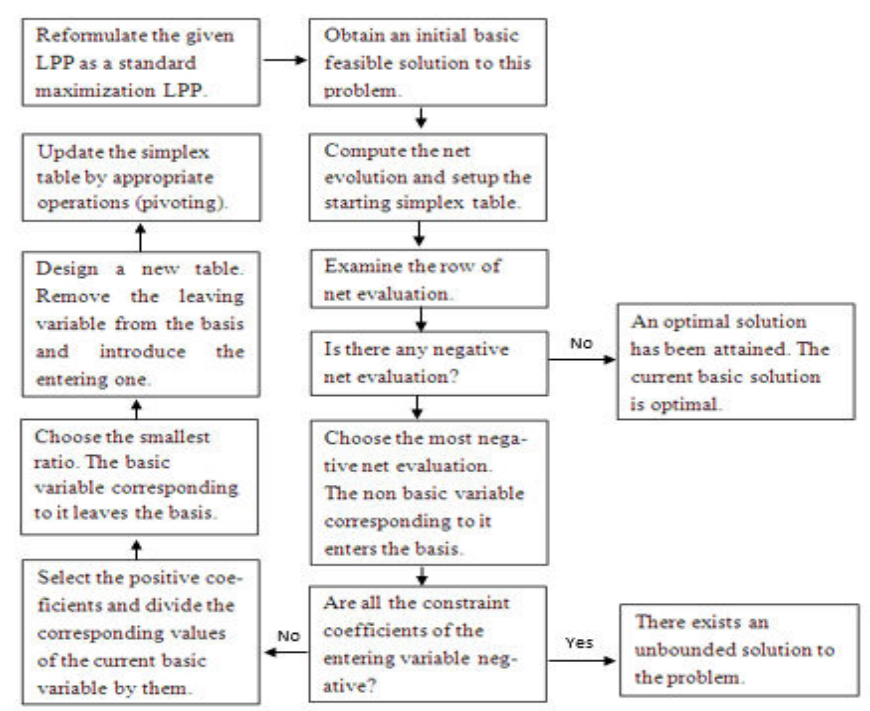

In Phase-I, the value of the non-natural variables are taken as -1 and those of other variables as zero. We find the targeted function as -

$\max Z^{*}=\left(-x_{n+1}-x_{n+2} \cdots \cdots \cdots \cdots-x_{n+m}\right)$

The constraints being stable. The problem then is solved by Simplex system. As each $X_{n+i}, i=$ $1 \cdots \cdots \cdots m$ is non-negative, in the most of the new targeted function is expected to be zero. Now three cases arise:

(1) Max. $Z^{*}=0$ And the non-natural variables are all removed from the basis.

(2) Max. $Z^{*}<0$ And some the non-natural variables show up in the basis at a positive level.

(3) Max. $Z^{*}=0$ And some the non-natural variables show up in the basis with value zero.

In case (1) we get a primary general feasible solution to the given LP problem and then proceed to find outstanding solution in Phase-II. In case (2) no feasible solution exists to the given LPP and hence we do not go to Phase-II to get outstanding solution. In case (3), we may or may not get a best general feasible solution to the real problem. But we move to Phase-II to get a best general feasible solution, if it survives. In PhaseII, we consider the actual costs related with the variables in the targeted function and assign a cost 0 to the non-natural variables. We now use the Simplex UniversePG I www.universepg.com system to the modified simplex table obtained at the end of Phase-I.

\section{Properties of the Simplex System}

The important properties of the simplex system are summarized as follows.

1) The simplex System for minimizing the targeted function starts at a feasible solution for the equivalent model and moves to an adjacent general possible solution that does not increase the value of the targeted function. However, a best solution for the real model has been reached, if such a result doesn't exist. That is, if all of the portions of the non-general variables in the targeted function equation are less than or equal to 0 (zero) at some point, also an optimal result for the real model has been reached. If such a result does not keep going or live, a best result for the real model has been reached. That's, if all coefficients of the non-basic variables in the targeted function equation are bigger than or equal to 0 at some given point, also a best result for the real model has been reached.

2) If anon-natural variable is in a classic solution of the equivalent model at a non-zero level, then no possible solution for the real model exists. On the contrary, if the classical solution of equivalent model does not contain anon-natural variable at a non-zero level, the solution is also classical for the original model.

3) If all of the slack, surplus, and non-natural are zero when an classical solution of the equivalent model is reached, also all of the constraints in the real model are strict "equivalence" for the values of the variables that optimize the targeted function.

4) If a non-basic variable has a 0 (zero) coefficient in the targeted function equation when a classic solution is reached, there are multiple classic solutions. In fact, there's perpetuity of optimal result. The simplex system finds only one optimal result and stops.

5) Once anon-natural variable leaves the pair of general variables (the basis), it will never enter the basis again. So all calculations for that variable can be ignored in next steps. 
6) When selecting the variable to leave the current basis:

A. If two or more ratios are smallest, choose one arbitrary.

B. If a non-negative ratio does not exist, the targeted function in the real model is not bounded by the constraints. Therefore, a finite optimal result for the real model does not existence.

7) If a basis has a variable at the 0 (zero) level, it is said a degenerate basis.

8) While cycling is possible, without any practical problems for which the simplex system break down to converge.

\section{FORTRAN Program for solving simplex method}

In this paper, our intent is to formulate linear programming model of some large-scale real life oriented problems and to apply computer program for solving these. Computer programs have been written with the help of Ali, (2001), Lipchitz, (2002) and Reddy, (1999) for the simplex algorithm that can take advance of special forms of the model. The FORTRAN computer program for solving LP is given bellow.

\section{FORTRAN Program}

\begin{tabular}{|c|c|}
\hline \multirow{2}{*}{\multicolumn{2}{|c|}{ 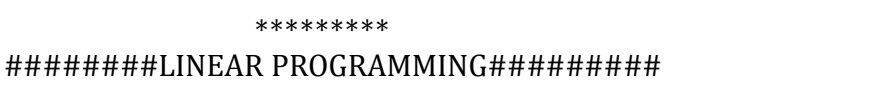 }} \\
\hline & \\
\hline ! & $* * * * * * * * * *$ SIMPLEX METHOD $* * * * * * * * * *$ \\
\hline \multicolumn{2}{|r|}{ ! $* * * * * * * * * * * * * * * * * * * * * * * * * * * * * * * * * * * * * * * * * * * * * * * * * * * * * * * * *$} \\
\hline & $* * * * * * * * *$ \\
\hline \multicolumn{2}{|c|}{ ! LIST OF MAIN VARIABLES: } \\
\hline \multicolumn{2}{|c|}{$!$} \\
\hline ! C: & MAXIMIZE $=1$, MINIMIZE $=2$ \\
\hline ! $\mathrm{N}:$ & NUMBER OF VARIABLES OF ECONOMIC FUNCTION \\
\hline & (TO MAXIMIZE OR MINIMIZE). \\
\hline ! M: & NUMBER OF CONSTRAINTS \\
\hline ! M1: & NUMBER OF $<=$ CONSTRAINTS \\
\hline ! M2: & NUMBER OF $>=$ CONSTRAINTS \\
\hline ! M3: & NUMBER OF $=$ CONSTRAINTS \\
\hline \multicolumn{2}{|c|}{ ! A, M, N, MP, NP, M1, M2, AND M3 ARE INPUT } \\
\hline \multicolumn{2}{|c|}{ PARAMETERS } \\
\hline \multicolumn{2}{|c|}{ ! ICASE, IZROV, AND IPOSV ARE OUTPUT PARAMETERS } \\
\hline \multicolumn{2}{|c|}{ ! MMAX: IS THE MAXIMUM NUMBER OF } \\
\hline \multicolumn{2}{|c|}{ CONSTRAINTS SXPECTED } \\
\hline \multicolumn{2}{|r|}{ ! MMAX: IS THE MAXIMUM NUMBER OF VARIABLES SXPECTED } \\
\hline \multicolumn{2}{|c|}{ ! EPS: $\quad$ IS THE ABSOLUTE PRECISION, } \\
\hline \multicolumn{2}{|c|}{ ! WHICH SHOULD BEADJUSTED TO THE SEALE OF } \\
\hline YOUR & VARIABLES \\
\hline
\end{tabular}



UniversePG I www.universepg.com

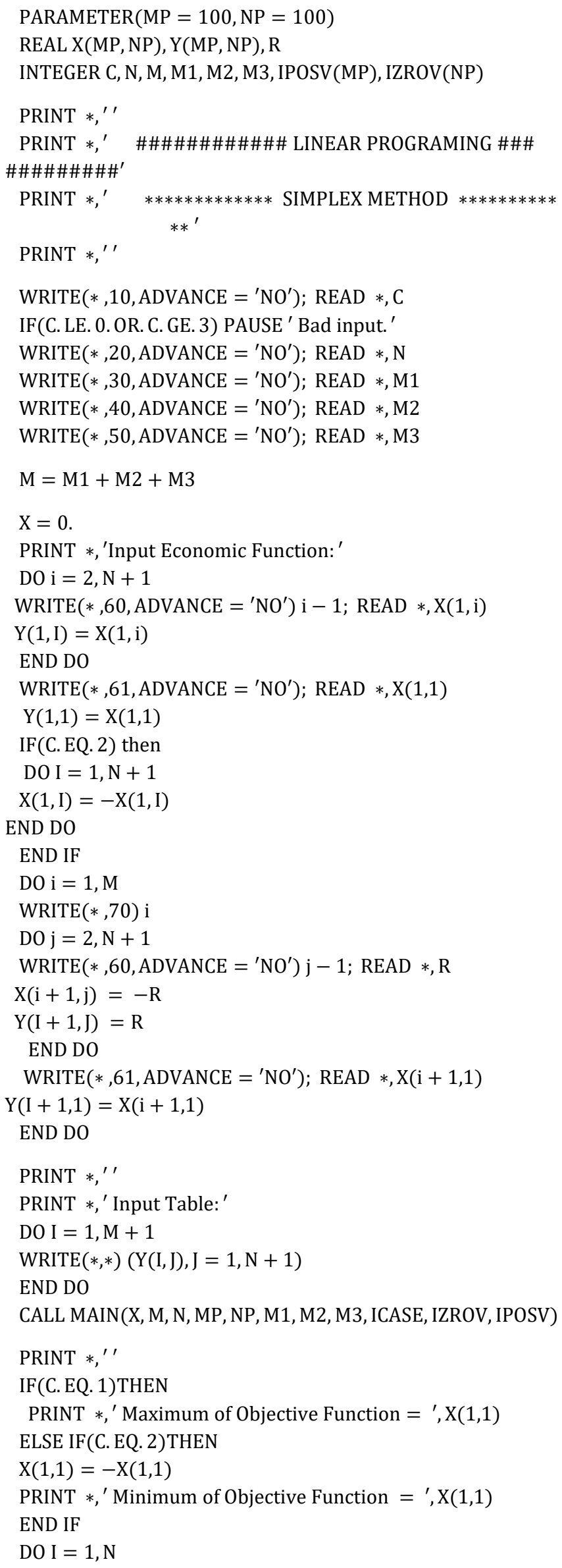




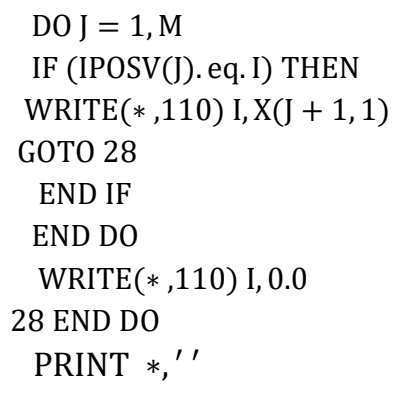

! Initial lefthand variables. $\mathrm{m} 1$ type constraints are represented by having their slackv ariable

! initially lefthand, with no non - natural variable. m2 type constraints have their slack

! variable initially lefthand, with a minus sign, and their non

$$
\text { - natural variable handled implicitly }
$$

! during their first exchange. $\mathrm{m} 3$ type

UniversePG I www.universepg.com constraints have their non - natural variable initially ! left - hand.

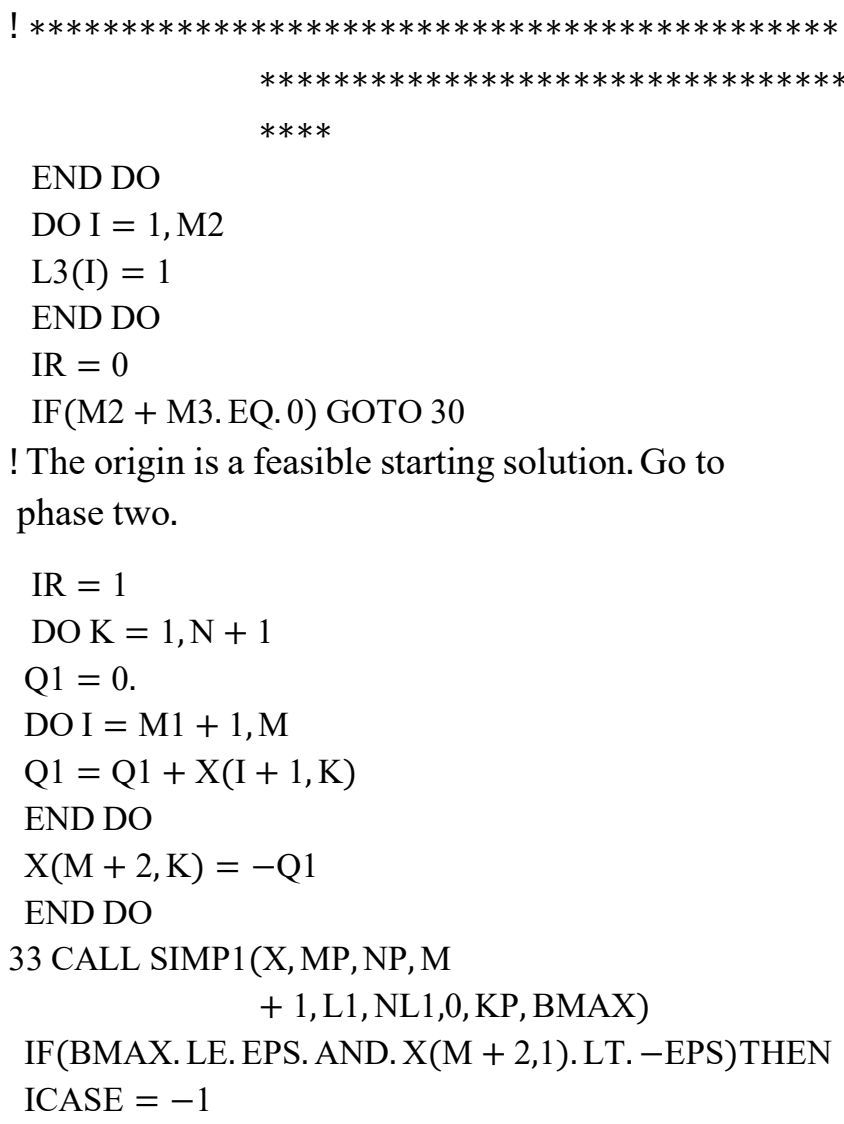

! The origin is a feasible starting solution. Go to phase two.

! Auxiliary objective function is still negative and can't be improved,

RETURN ! hence no feasible solution exists. ELSE IF(BMAX. LE. EPS. AND. X(M

$$
+2,1) \text {. LE. EPS)THEN }
$$

! Auxiliary objective function is zero and can't be improved; we have a feasible starting vector.

! Clean out the non

$$
\text { - natural variables corresponding to }
$$

any remaining equality constraints by

! goto 1's and then move on to phase two by goto 30 .

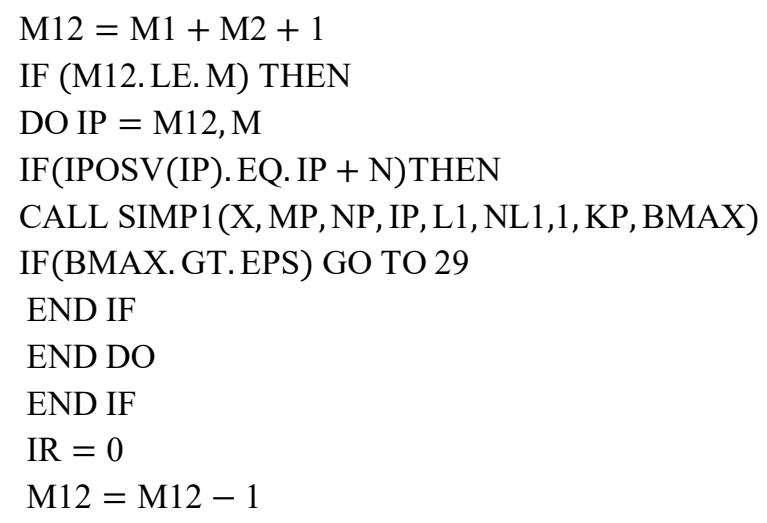




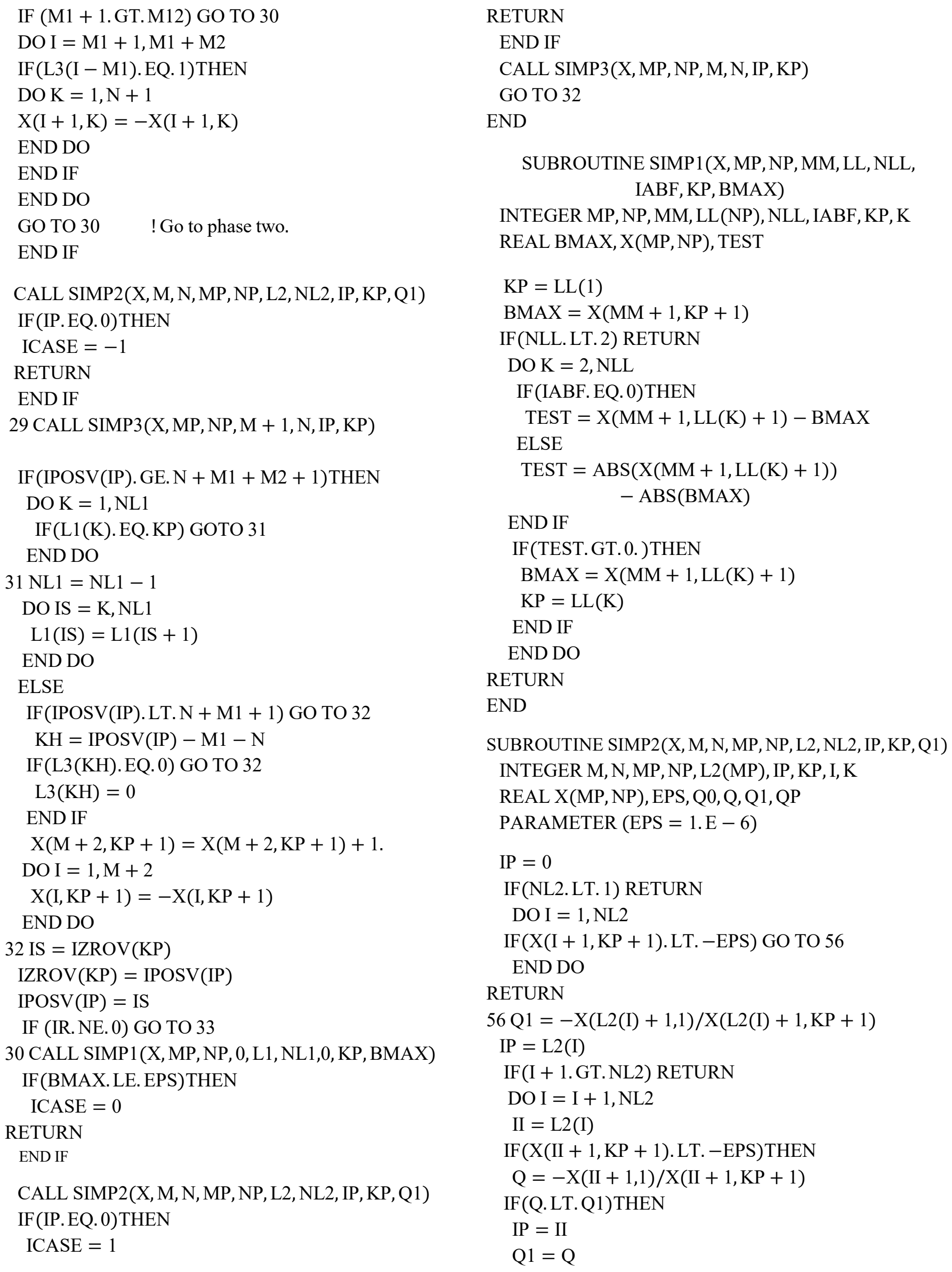




$$
\begin{aligned}
& \text { ELSE IF (Q. EQ. Q1) THEN } \\
& \text { DO K }=1, \mathrm{~N} \\
& \text { QP }=-\mathrm{X}(\mathrm{IP}+1, \mathrm{~K}+1) / \mathrm{X}(\mathrm{IP}+1, \mathrm{KP}+1) \\
& \text { Q0 }=-\mathrm{X}(\mathrm{II}+1, \mathrm{~K}+1) / \mathrm{X}(\mathrm{II}+1, \mathrm{KP}+1) \\
& \text { IF(Q0. NE. QP) goto } 57 \\
& \text { END DO }
\end{aligned}
$$

\section{Some real life problem of LPP}

By using above algorithm we can solved any LP problem. Some practical problem is given bellow.

\section{Problem}

Consider the following LPP:

Minimize, $\quad Z=x_{1}-3 x_{2}+2 x_{3}$

Subject to, $3 x_{1}-x_{2}+2 x_{3} \leq 7$

$-2 x_{1}+4 x_{2} \leq 12$

$-4 x_{1}+3 x_{2}+8 x_{3} \leq 10$

$x_{1}, x_{2}, x_{3} \geq 0$

We like to solve this problem by hand calculation and computer programming.

\section{Solution: (Analytic solution)}

We are now given Minimize, $\quad Z=x_{1}-3 x_{2}+2 x_{3}$

Subject to the constraints -

$3 x_{1}-x_{2}+2 x_{3} \leq 7$

$-2 x_{1}+4 x_{2} \leq 12$

$-4 x_{1}+3 x_{2}+8 x_{3} \leq 10$

$x_{1}, x_{2}, x_{3} \geq 0$

The given minimization problem can be written as

Maximize $Z^{\prime}=-Z=-x_{1}+3 x_{2}-2 x_{3}$

Introducing the unbound variabless $s_{1}, s_{2}, s_{3} \geq 0$ to the constraints we get the L.P.P. as to

Maximize, $Z^{\prime}=-x_{1}+3 x_{2}-2 x_{3}+0 . s_{1}+0 . s_{2}+0 . s_{3}$

Subject to, $3 x_{1}-x_{2}+2 x_{3}+s_{1}=7$

$-2 x_{1}+4 x_{2}+0 . x_{3}+s_{2}=12$

$-4 x_{1}+3 x_{2}+8 x_{3}+s_{3}=10$

wherex $_{1}, x_{2}, x_{3}, s_{1}, s_{2}, s_{3} \geq 0$

Construct the $1^{\text {st }}$ simplex Table as Table 3.

Table 3: Since $C_{j}-E_{j}$ is non negative under $x_{2}$ column, Table 1 is not optimal. In Table $1 x_{2}$ is incoming variable, $s_{2}$ is outgoing variable and (4) is the prime element.

In Table $3 s_{2}$ is restore by $x_{2}$ in the basis

\begin{tabular}{|c|c|cccccc|c|c|}
\hline & $C_{j}$ & -1 & 3 & -2 & 0 & 0 & 0 & \multicolumn{2}{|c|}{ Constant } \\
\cline { 2 - 10 }$C_{B}$ & Basis & $\mathrm{x}_{1}$ & $\mathrm{x}_{2}$ & $\mathrm{x}_{3}$ & $\mathrm{~s}_{1}$ & $\mathrm{~s}_{2}$ & $\mathrm{~s}_{3}$ & $b$ & $\theta$ \\
\hline 0 & $\mathrm{~s}_{1}$ & 3 & -1 & 2 & 1 & 0 & 0 & 7 & -7 \\
0 & $\mathrm{~s}_{2}$ & -2 & $(4)$ & 0 & 0 & 1 & 1 & 12 & $3 \leftarrow$ \\
0 & $\mathrm{~s}_{3}$ & -4 & 3 & 8 & 0 & 0 & 1 & 10 & $10 / 3$ \\
\hline
\end{tabular}

UniversePG I www.universepg.com

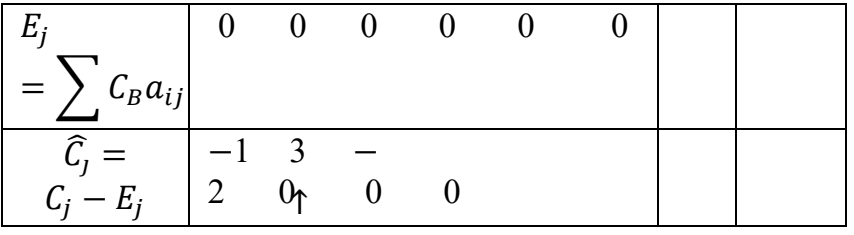

Table 4: Since $C_{j}-E_{j}$ is positive under $x_{1}$ column, second general feasible solution is not classical or optimal.

In Table $3 s_{1}$ is restored by $x_{1}$.

\begin{tabular}{|c|c|cccccc|c|c|}
\hline$C_{B}$ & $C_{j}$ & -1 & 3 & -2 & 0 & 0 & 0 & \multicolumn{2}{c|}{ Constant } \\
\cline { 2 - 10 } & Basis & $x_{1}$ & $x_{2}$ & $x_{3}$ & $s_{1}$ & $s_{2}$ & $s_{3}$ & $b$ & $\theta$ \\
\hline 0 & $s_{1}$ & $(5 / 2)$ & 0 & 2 & 1 & $1 / 4$ & 0 & 10 & $4 \leftarrow$ \\
3 & $x_{2}$ & $-1 / 2$ & 1 & 0 & 0 & $1 / 4$ & 0 & 3 & -6 \\
0 & $s_{3}$ & $-5 / 2$ & 0 & 8 & 0 & $-3 / 4$ & 1 & 1 & $-2 / 5$ \\
\hline \multicolumn{2}{|l|}{$E_{j}=\sum C_{B} a_{i j}$} & $-3 / 2$ & 3 & 0 & 0 & $3 / 4$ & 0 & & \\
\hline \multicolumn{2}{|l|}{$\widehat{C}_{j}=C_{j}-E_{j}$} & $1 / 2$ & 0 & -2 & 0 & $-3 / 4$ & 0 & & \\
\hline
\end{tabular}

Table 5: Since $C_{j}-E_{j}$ is either negative or zero under all variables, Table 3 is optimal.

The optimal general feasible solution is -

$x_{1}=4, x_{2}=5, x_{3}=0$

$Z^{\prime}=-4+3 \times 5-2 \times 0=11$

or $Z_{\text {min }}=-11$

\begin{tabular}{|l|l|lrrrrrr|c|}
\hline \multirow{3}{*}{$C_{B}$} & $C_{j}$ & -1 & 3 & -2 & 0 & 0 & 0 & Constant \\
\cline { 2 - 9 } & Basis & $x_{1}$ & $x_{2}$ & $x_{3}$ & $s_{1}$ & $s_{2}$ & $s_{3}$ & $\mathrm{~b}$ \\
\hline-1 & $x_{1}$ & 1 & 0 & $4 / 5$ & $2 / 5$ & $1 / 10$ & 0 & 4 \\
3 & $x_{2}$ & 0 & 1 & $2 / 5$ & $1 / 5$ & $3 / 10$ & 0 & 5 \\
0 & $s_{3}$ & 0 & 0 & 10 & 1 & $-1 / 2$ & 1 & 11 \\
\hline
\end{tabular}

Computer solution of the problem by using FORTRAN program.

Input of the problem:

\#\#\#\#\#\#\#\#\#\#\#\# LINEAR

PROGRAMING \#\#\#\#\#\#\#\#\#\#\#\#

\section{SIMPLEX METHOD}

Maximize or Minimize? [MAX $=1, \operatorname{MIN}=2] \ldots: 2$

Number of non - basic variables: 3

Number of $<=$ inequalities. .: 3

Number of $>=$ inequalities. .: 0

Number of $=$ equalities.....: 0

Input Economic Function:

Coefficient \# 1: 1

Coefficient \# 2: -3 
Coefficient \# 3: 2

Constant term. .: 0

Input constraint \# 1:

Coefficient \# 1: 3

Coefficient \# 2: -1

Coefficient \# 3: 2

Constant term.. : 7

Input constraint \# 2:

Coefficient \# 1: -2

Coefficient \# 2: 4

Coefficient \# 3: 0

Constant term. . : 12

Input constraint \# 3:

Coefficient \# 1: -4

Coefficient \# 2: 3

Coefficient \# 3: 8

Constant term. . : 10

\section{Output of the problem}

Input Table:

$0.0000000 \mathrm{E}+00 \quad 1.000000$

$\begin{array}{rrr} & -3.000000 & 2.000000 \\ 7.000000 & 3.000000 & \\ & -1.000000 & 2.000000\end{array}$

12.00000

$\begin{array}{lll}-2.000000 & 4.000000 & 0.0000000 \mathrm{E}+00\end{array}$

10.00000

$-4.000000 \quad 3.000000 \quad 8.000000$

Minimum of Objective Function $=-11.00000$

$\mathrm{X} 1=4.000000$

$\mathrm{X} 2=5.000000$

$\mathrm{X} 3=0.000000$

We concluded that the analytical solution and computer solution are same so our program is right for any LPPs. Now we formulate two large size real-life LPPs which are very difficult to calculate by analytical process. But by using computer programming we can solve that problem very easily.

\section{Problem (Bank Loan Policy)}

From the problem 2.2 which is formulated in the previous chapter now we solve this by using FORTRAN program.

\section{Solution}

The targeted function is given as

$$
\begin{aligned}
& \text { Maximize } Z=.026 x_{1}+.0509 x_{2}+.0864 x_{3} \\
& +.06875 x_{4}+.078 x_{5}
\end{aligned}
$$

Subject to $x_{1}+x_{2}+x_{3}+x_{4}+x_{5} \leq 12$

$$
\begin{aligned}
& x_{4}+x_{5} \geq 4.8 \\
& .5 x_{1}+.5 x_{2}-.5 x_{3} \leq 0 \\
& .06 x_{1}+.03 x_{2}-.01 x_{3}+.01 x_{4}-.02 x_{5} \leq 0 \\
& \text { where, } x_{1} \geq 0, x_{2} \geq 0, x_{3} \geq 0, x_{4} \geq 0, x_{5} \geq 0
\end{aligned}
$$

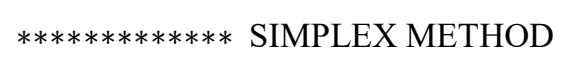

Maximize or Minimize? [MAX $=1, \mathrm{MIN}=2] \ldots: 1$

Number of non - basic variables: 5

Number of $<=$ inequalities. . : 3

Number of $>=$ inequalities. .: 1

Number of $=$ equalities....: 0

Input Economic Function:

Coefficient \# 1:.026

Coefficient \# 2: .0509

Coefficient \# 3: .0864

Coefficient \# 4: .06875

Coefficient \# 5: .078

Constant term. .: 0

Input constraint \# 1:

Coefficient \# 1: 1

Coefficient \# 2: 1

Coefficient \# 3: 1

Coefficient \# 4: 1

Coefficient \# 5: 1

Constant term. . : 12

Input constraint \# 2:

Coefficient \# 1: 0

Coefficient \# 2: 0

Coefficient \# 3: 0

Coefficient \# 4: 1

Coefficient \# 5: 1

Constant term. . : 4.8

Input constraint \# 3:

Coefficient \# 1: .5

Coefficient \# 2: .5

Coefficient \# 3: $\quad-.5$

Coefficient \# 4: 0

Coefficient \# 5: 0

Constant term. . : 0

Input constraint \# 4:

Coefficient \# 1: .06

Coefficient \# 2: .03

Coefficient \# 3: -.01

Coefficient \# 4: .01 
Coefficient \# 5: $\quad-.02$

Constant term. .: 0

\section{Output of the problem}

Input Table:

$\begin{array}{ccc}0.0000000 \mathrm{E}+00 & 2.6000001 \mathrm{E}-02 & 5.0900001 \mathrm{E} \\ & -02 & 8.6400002 \mathrm{E}-02 \\ 6.8750001 \mathrm{E}-02 & 7.8000002 \mathrm{E}-02 \\ 12.00000 & 1.000000 & 1.000000 \\ 1.000000 & 1.000000 \\ 1.000000 & \\ 4.800000 & 0.0000000 \mathrm{E}+00 \quad 0.0000000 \mathrm{E} \\ & +00 & 0.0000000 \mathrm{E}+00 \quad 1.000000\end{array}$

1.000000

$\begin{array}{rrl}0.0000000 \mathrm{E}+00 & 0.5000000 & 0.5000000 \\ -0.5000000 & 0.0000000 \mathrm{E}+00\end{array}$

$0.0000000 \mathrm{E}+00$

$0.0000000 \mathrm{E}+005.9999999 \mathrm{E}-022.9999999 \mathrm{E}-02$

$-9.9999998 \mathrm{E}-03$

$9.9999998 \mathrm{E}-03-2.0000000 \mathrm{E}-02$

Maximum of Objective Function $=0.9332572$

$\mathrm{X} 1=1.714287$

$\mathrm{X} 2=0.000000$

$\mathrm{X} 3=10.285713$

$\mathrm{X} 4=0.000000$

$\mathrm{X} 5=0.000000$

\section{Problem (Car Scheduling Problem)}

Progressing City is studying the feasibility of introducing a mass transit car system that will alleviate the smog problem by reducing in city driving. In this study find the resolve of the lowest number of cars that could handle the transportation needs. After taking some necessary information, the town engineers observed that the lowest number of cars needed vary with the time of the day and that the recommended number of cars could be approximated by constant values over successive 4-hour intervals. In the figure summarizes the engineers finding. To carry through the recommended daily maintenance, each car can operate only 8 successive hours a day.

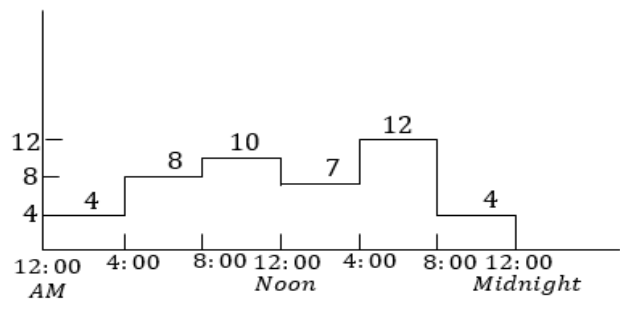

UniversePG I www.universepg.com

\section{Mathematical Representation}

Establish the number of operating cars in every switch that will meet the lowest demand while minimizing the all number of cars in operation. You may already have observed that the contrast of the variables is unfixed. We know that every car will run for 8 hours, but we don't know when a switch should start. If we follow a basic 3(three) switch schedule (8:01A.M to 4:00 P.M., 4:01P.M. to 12.00 midnight, and 12.01A.M.to 8:00 A.M.) and take that $x_{1}, x_{2}$ and $x_{3}$ are the number of cars starting in the $1^{\text {st }}, 2^{\text {nd }}$ and $3^{\text {rd }}$ shifts, we can notice from the top of figure that $x_{1} \geq 10, x_{2} \geq 12$ and $x_{3} \geq 8$. The corresponding lowest number of every day cars is $x_{1}+x_{2} x_{3}=10+12+8=30$. The given solution is accepted, if the switch should be coincide with the normal 3(three) switch schedule. It can be beneficial, moreover, to allow the optimization process to choose the top beginning time for a switch, a reasonable way to accomplish this is allow a switch to begin every 4 hours. The foot of figure illustrates this idea where overlapping switch can start at $12.01 \mathrm{am}$, 4.01am, 8.01am, $12.01 \mathrm{pm}, 4.01 \mathrm{pm}$ and $8.01 \mathrm{pm}$ with every switch spanning 8 successive hours.

Thus, the variables can be defined as -

$x_{1=}$ number of cars starting at 12.01 A.M.

$x_{2}=$ number of cars starting at 4.01 A.M.

$x_{3}=$ number of cars starting at 8.01 A.M.

$x_{4}=$ number of cars starting at 12.01 P.M.

$x_{5}=$ number of cars starting at 4.01 P.M.

$x_{6}=$ number of cars starting at 8.01 P.M.

The mathematical model is written as -

Minimize

$z=x_{1}+x_{2}+x_{3}+x_{4}+x_{5}+x_{6}$

Subject to $x_{1}+x_{6} \geq 4$ (12.01 A.M. -4.00 A.M.)

$x_{1}+x_{2} \geq 8$ (4.01 A. M. -8.01 A.M. $)$

$x_{2}+x_{3} \geq 10(8.01$ A. $\mathrm{M}-12.00$ noon $)$

$x_{3}+x_{4} \geq 7(12.01$ P.M. -4.01 P.M.)

$x_{4}+x_{5} \geq 12$ (4.01 P.M. -8.00 P.M.)

$x_{5}+x_{6} \geq 4$ (8.01 P.M. -12.00 P.M. $)$

$x_{j} \geq 0, j=1,2, \ldots \ldots 6$

Computer solution of the problem by using FORTRAN program.

Input of the problem

\#\#\#\#\#\#\#\#\#\#\# LINEAR

PROGRAMING \#\#\#\#\#\#\#\#\#\#\#\#

SIMPLEX METHOD $* * * * * * * * * * * *$ 
Maximize or Minimize? $[\mathrm{MAX}=1, \mathrm{MIN}=2] . .: 2$

Number of non - basic variables: 6

Number of $<=$ inequalities. .: 0

Number of $>=$ inequalities. .: 6

Number of $=$ equalities.....: 0

Input Economic Function:

Coefficient \# 1: 1

Coefficient \# 2: 1

Coefficient \# 3: 1

Coefficient \# 4: 1

Coefficient \# 5: 1

Coefficient \# 6: 1

Constant term. . : 0

Input constraint \# 1:

Coefficient \# 1: 1

Coefficient \# 2: 0

Coefficient \# 3: 0

Coefficient \# 4: 0

Coefficient \# 5: 0

Coefficient \# 6: 1

Constant term..: 4

Input constraint \# 2:

Coefficient \# 1: 1

Coefficient \# 2: 1

Coefficient \# 3: 0

Coefficient \# 4: 0

Coefficient \# 5: 0

Coefficient \# 6: 0

Constant term. .: 8

Input constraint \# 3:

Coefficient \# 1: 0

Coefficient \# 2: 1

Coefficient \# 3: 1

Coefficient \# 4: 0

Coefficient \# 5: 0

Coefficient \# 6: 0

Constant term. .: 10

Input constraint \# 4:

Coefficient \# 1: 0

Coefficient \# 2: 0

Coefficient \# 3: 1

Coefficient \# 4: 1

Coefficient \# 5: 0

Coefficient \# 6: 0

Constant term. .: 7

Input constraint \# 5:
Coefficient \# 1: 0

Coefficient \# 2: 0

Coefficient \# 3: 0

Coefficient \# 4: 1

Coefficient \# 5: 1

Coefficient \# 6: 0

Constant term. . : 12

Input constraint \# 6:

Coefficient \# 1: 0

Coefficient \# 2: 0

Coefficient \# 3: 0

Coefficient \# 4: 0

Coefficient \# 5: 1

Coefficient \# 6: 1

Constant term. . : 4

\section{Output of the problem:}

Input Table:

0.0000000E

$\begin{array}{llll}+00 & 1.000000 & 1.000000 & 1.000000\end{array}$

1.000000

$1.000000 \quad 1.000000$

$\begin{array}{llll}4.000000 & 1.000000 & 0.0000000 \mathrm{E}+00 & 0.0000000 \mathrm{E}\end{array}$ $+000.0000000 \mathrm{E}+00$

$0.0000000 \mathrm{E}+00 \quad 1.000000$

$\begin{array}{llll}8.000000 & 1.000000 & 1.000000 & 0.0000000 \mathrm{E}\end{array}$ $+000.0000000 \mathrm{E}+00$

$0.0000000 \mathrm{E}+000.0000000 \mathrm{E}+00$

$10.00000 \quad 0.0000000 \mathrm{E}$

$\begin{array}{llll}+00 & 1.000000 & 1.000000 & 0.0000000 \mathrm{E}+00\end{array}$

$0.0000000 \mathrm{E}+00 \quad 0.0000000 \mathrm{E}+00$

$7.000000 \quad 0.0000000 \mathrm{E}+00 \quad 0.0000000 \mathrm{E}$ $+\begin{array}{lll}00 & 1.000000 & 1.000000\end{array}$

$0.0000000 \mathrm{E}+000.0000000 \mathrm{E}+00$

$12.00000 \quad 0.0000000 \mathrm{E}+00 \quad 0.0000000 \mathrm{E}$

$+00 \quad 0.0000000 \mathrm{E}+00 \quad 1.000000$

$1.000000 \quad 0.0000000 \mathrm{E}+00$

$4.000000 \quad 0.0000000 \mathrm{E}+00 \quad 0.0000000 \mathrm{E}+00 \quad 0.0000000 \mathrm{E}$ $+000.0000000 \mathrm{E}+00$

$1.000000 \quad 1.000000$

Minimum of Objective Function $=26.00000$

$\mathrm{X} 1=4.000000$

$\mathrm{X} 2=10.000000$

$\mathrm{X} 3=0.000000$

$\mathrm{X} 4=8.000000$

$\mathrm{X} 5=4.000000$

$\mathrm{X} 6=0.000000$ 


\section{A Real Life Problem of Transportation Problem and Its Solution}

\section{Transportation Problem}

One of the advance and most practical applications of LP techniques has been solution and the formulation of the transportation problem. The mathematical formulation of this problem gives us an LPP which in revolve can be solved by the simplex system, revised system or dual simplex system but the special structure of the measure matrix is such that more efficient methods can be used to solve these problems easily. We shall discuss here the Vogel's approximation method and the North-West Corner rule to solve such problems. For some other methods like stepping stone algorithm the students can consult Hadley, (1962) and Rao, (2005). The basic transportation problem was originally stated by Hitchcock, (1941) and later discussed in detail by Kopman, (1949). An earlier approach was provided Kantorovich, (1958). The linear programming formulation and the associated systematic method for solution were first given in Danzig, (1951)

\section{Formulation of General Transportation Problem}

A homogeneous product available at a fixed number of origins is to be transported to a fixed number of destinations. All of amount available at every of these origins is known and also the all quantity needed at every destination is known. The unit transportation value from every origin to each destination is given. The question then's to determine the quantum of the products to be transported from these origins to be destinations so, as to minimize the total transportation cost. If mis the number of root or origin and nis the number of goal or destinations the value of transporting 1 unit of the commodity from root $i$ to goaljis $c_{i j}$. If $a_{i}$ be the quantity of the commodity available at root $i$ and $b_{j}$ be the quantity required at destination $j$. Thus $a_{j} \geq 0$ for $i$ and $b_{j} \geq 0$ for each $j$. If $x_{i j}$ is the quantity transported from origin $i$ to destination $j$ we write the general formulation of the transportation problem as

Minimize $Z=\sum_{i=1}^{m} \sum_{j=1}^{n} c_{i j} x_{i j}$

Subject to $\sum_{j=1}^{n} x_{i j}=a_{i}, i=1,2, \ldots \ldots \ldots \ldots m$ $\sum_{i=1}^{n} x_{i j}=b_{i}, i=1,2, \ldots \ldots \ldots \ldots n$

$x_{i j} \geq 0$.

The above represents a LPP with $m n$ variables and $m+n$ constraints. To see the unique structure of the co-efficient matrix here we take a special case for $m=2$ and $n=3$. The mnvariables from a vector $X=\left(x_{11}, x_{12}, x_{13}, x_{21}, x_{22}, x_{23}\right)^{T}$.

The vector $b=\left(a_{1}, a_{2}, b_{1}, b_{2}, b_{3}\right)^{T}$, and

$C=\left(c_{11}, c_{12}, c_{13}, c_{21}, c_{22}, c_{23}\right)$. Then the transportation problem may be written as

$\operatorname{Min} Z=C X$

Subject to $A X=b$

$X \geq 0$.

Where $A$ is a $5 \times 6$ matrix. The exact form of $A$ is -

$\left[\begin{array}{llllll}1 & 1 & 1 & 0 & 0 & 0 \\ 0 & 0 & 0 & 1 & 1 & 1 \\ 1 & 0 & 0 & 1 & 0 & 0 \\ 0 & 1 & 0 & 0 & 1 & 0 \\ 0 & 0 & 1 & 0 & 0 & 1\end{array}\right]$

Note that, each column of the matrix $A$ contains 1 exactly in two places. For the basic transportation problem the order of matrix $A$ will be $(m+n) \times(m n)$, that of the column vector $X$ will be $(m n) \times 1$, that of the column vector $b$ will be $(m+n) \times 1$ and of the row vector $C$ will be $1 \times(m n)$.

\section{Unbalanced Transportation Problem}

A transportation problem is claimed to be balanced if

$\sum_{i=1}^{m} a_{i}=\sum_{j=1}^{n} b_{j}$

Else, it's said to be unbalanced. Suppose,

$\sum_{i=1}^{m} a_{i}>\sum_{j=1}^{n} b_{j}$

Then a fictitious destination is considered with requirement

$\sum_{i=1}^{m} a_{i}-\sum_{j=1}^{n} b_{j}$

The unit cost of transportation to this destination from all the $m$ origins may be taken as zero. On the contrary, suppose

$\sum_{i=1}^{m} a_{i}<\sum_{j=1}^{n} b_{j}$ 
Then a fictitious origin can be taken with available quantity -

$\sum_{i=1}^{m} b_{j}-\sum_{j=1}^{n} a_{i}$.

The unit cost of transportation from this factious root to all the $n$ goal will be as 0 (zero). This way an unstable problem can be stable.

\section{Finding Initial general Feasible Solution}

The general transportation problem should be represented in a table form -

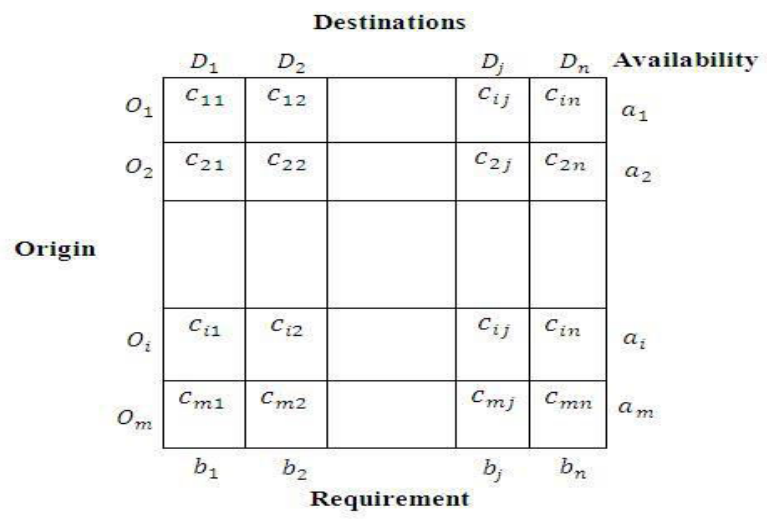

This Table has $m n$ cells.

\section{The North-West Rule}

Following steps are involved in this method:

\section{Step 1}

Make the first assignment to the upper-left hand cell which is called North-West Corner. Take $x_{11}=$ $\min \left(a_{1}, b_{1}\right)$

\section{Step 2}

If $x_{11}=a_{1}$, then row I can be deleted. If $x_{11}=b_{1}$, then column I can be deleted. In the first case replace $b_{1}$ by $b_{1}-a_{1}$ and in the second case replace $a_{1}$ by $a_{1}-b_{1}$

\section{Step 3}

If $a_{1}=b_{1}$, then $x_{11}=a_{1}=b_{1}$ and row I as well as column I will be deleted. The gives anindication that a degenerate basic feasible solution will be obtained, that is, not more than $m+n-1$ positive basic variables will be obtained.

\section{Step 4}

A new matrix of order $(m-1) \times n$, ormx $(n-$ $1) \operatorname{or}(m-1) \times(n-1)$ will appear. This are called the reduce matrices. Repeat steps 1-3 till all of the quantities are wasted. This is likely or possible as it is a balanced problem.

\section{The Vogel's approximation system}

Vogel's Approximation system is a heuristic method and is preferred to the methods describe above. In the transportation matrix if an allocation is made in the alternate smallest cost cell rather of the smallest, also this allocation will have associated with it a penalty corresponding to the difference of these two costs due to loss of advantage. That is to say, if we cipher the difference between the two smallest costs for each row and column, we find the occasion cost applicable to each row and column. It would be most provident to make allocation against the row or column with the loftiest occasion cost. For a given row or column, the allocation should obviously be made in the list cost cell of that row or column. Vogel's approximation method there for, makes effective use of the cost information and yields a better initial solution then obtained by the other method.

\section{Some real life problem of LPP}

Some practical problem is given bellow.

\section{Problem}

A transportation problem for maximum profits is that

\begin{tabular}{|l|lllr|c|}
\hline $\mathrm{A}$ & $\mathrm{B}$ & $\mathrm{C}$ & $\mathrm{D}$ & Supply \\
\hline 12 & 18 & 6 & 25 & 200 \\
& 8 & 7 & 10 & 18 & 500 \\
Demand & 14 & 3 & 11 & 20 & 300 \\
\cline { 2 - 6 } & 180 & 320 & 100 & 400 & \\
\hline
\end{tabular}

We want to solve this problem by hand calculation.

\section{Solution: (Analytic solution)}

By using North-West Corner rule we solved this problem, which given bellow:

\begin{tabular}{|c|c|c|c|}
\hline$B$ & C & $D$ & Supply \\
\hline$\ldots 18 \times 20$ & $\ldots$ & .....25 & $\ldots 200 / 20 \ldots$ \\
\hline $7 \times 300$ & $10 \times 100$ & $18 \times 100$ & $500 / 100$ \\
\hline 3 & 11 & $20 \times 300$ & 300 \\
\hline 320 & 100 & $400 / 300$ & \\
\hline
\end{tabular}

\begin{tabular}{|c|c|c|c|c|}
\hline$A$ & $B$ & $\bar{C}$ & $\bar{D}$ & Supply \\
\hline $12 \times 180$ & $18 \times 20$ & & & $200 / 20$ \\
\hline & $7 \times 300$ & $10 \times 100$ & $18 \times 100$ & $500 / 100$ \\
\hline & & & $20 \times 300$ & 300 \\
\hline 180 & 320 & 100 & $400 / 300$ & \\
\hline
\end{tabular}


It's a balanced transportation problem. Here $m+n-$ $1=3+4-1=6$. We get the required degenerate general feasible solution as -

$$
\begin{aligned}
& =12 \times 180+18 \times 20+7 \times 300+10 \times 100+18 \\
& \quad \times 100+20 \times 300 \\
& =2160+360+2100+1000+1800+6000 \\
& =13420
\end{aligned}
$$

\section{Problem}

A dairy establishment has three shops located throughout a state. Every milk production at each factory is as follows -

Factory 1.........6 million liters,

Factory 2.......... 1 million liters, and

Factory 3 ..........10 million liters.

Every day the establishment must fulfill the requirements of its four Delivery points. Minimum demand at each point is as follows -

Delivery point 1 . .7 million liters,

Delivery point 2.............5 million liters,

Delivery point 3.............3 million liters, and

Delivery point 4 ............2 million liters.

Cost of dispatching one million liters of milk from each factory to each Delivery point is given in the following -

\begin{tabular}{l|l|l|l|l|l}
\multicolumn{1}{l}{1} & 2 & 3 & 4 & supply \\
1 & 2 & 3 & 11 & 7 & 6 \\
2 & 1 & 0 & 6 & 1 & 1 \\
3 & 5 & 8 & 15 & 9 & 10 \\
\cline { 2 - 4 } Demand & 7 & 5 & 3 & 2 &
\end{tabular}

\section{Solution: (Analytic solution)}

\begin{tabular}{|c|c|c|c|c|c|}
\hline & 1 & 2 & 3 & 4 & supply \\
\hline 1 & 2 & 3 & 11 & 7 & $6(1)$ \\
\hline 2 & 1 & 0 & 6 & 1. & $1 / 0(1)$ \\
\hline 3 & 5 & 8 & 15 & 9 & $10(3)$ \\
\hline Demand & 7 & 5 & 3 & 2 & \\
\hline
\end{tabular}

By using Vogel's approximation method we solved this problem, which is given bellow:

Step 1: Write down the cost matrix.
(3) (5)
(6)

Enter the difference between the lowest and second lowest elements in each column below the corresponding column and the difference between the lowest and second lowest elements in each row to the write of the row put these numbers in brackets as shown. For example, in column 1, the two lowest elements are 1 and 2 and there difference is 1 which is entered (1) below column 1. Similarly, the 2 smallest elements in row 2 are 0 and 1 and their difference 1 is entered as (1) to the right of row 2. A row or column difference indicates the unite plenitude incurred falling to make an allocation to the smallest cost cell in that row or column

Step 2: Select the row or column with the highest difference and allocate as much as possible with in the restrictions of the rim conditions to the smallest cost cell in the row or column selected. In case a tie occurs, assign to the cell related with the smallest cost. Thus since (6) is the largest number in brackets, we choose column 4 and allocate as much as possible to the cell $(2,4)$ as it has the lowest cost 1 in column 4 . Since supply is 1 while the requirement is 2 , highest possible allocation is (1).

Step 3: Cross out the row or column fully satisfied by the allocation just made. For the assignment just made

\begin{tabular}{|c|c|c|c|c|c|}
\hline & 1 & 2 & 3 & 4 & supply \\
\hline 1 & 2 & $3_{(5)}$ & 11 & 7 & $6 / 1$ \\
\hline 3 & 5 & 8 & 15 & 9 & $10(3)$ \\
\hline emand & $\begin{array}{l}7 \\
(3)\end{array}$ & $\begin{array}{l}5 \\
(5)\end{array}$ & $\begin{array}{l}3 \\
\text { (4) }\end{array}$ & $\begin{array}{l}1 \\
\text { (2) }\end{array}$ & \\
\hline
\end{tabular}
at $(2,4)$, supply of plant 2 is completely satisfied. So row 2 is crossed out and the shrunken matrix is written below.

This matrix involve of the columns and row where allotment have not been yet made, together with revised column and row summation, which consider the formerly made allocation.

Step 4: Reprise way 1 to 3 until all assignments have been made (a) column 2 exhibits the top most difference of (5). Therefore, we allocate (5) units to cell $(1,2)$, since it has the smallest transportation cost in column 2. Since condition of column 2 are fully satisfied, this column is cross out and the reduced matrix is written. 


\begin{tabular}{|c|c|c|c|c|}
\hline & 1 & 3 & 4 & supply \\
\hline 1 & $z-$ & $-11-$ & $-7-1$ & $-1 / 0(5) \leftarrow$ \\
\hline 3 & 5 & 15 & 9 & $10(3)$ \\
\hline
\end{tabular}

\section{(3) (4) (2)}

(b) Difference is recalculated. The maximum difference is (5).Therefore, we allocate (1) to the cell (1, 1) since it has the lowest cost in row 1 . Since requirements of row 1 are fully satisfied, it is crossed out and the reduced matrix is written below.

\begin{tabular}{|c|c|c|c|}
\hline & 1 & 3 & 4 \\
\hline 3 & 5 & $-1^{-} 5_{(3)}^{---}$ & $-\theta_{(1)}^{--}$ \\
\hline emand & $6 / 0$ & $3 / 0$ & $1 / 0$ \\
\hline
\end{tabular}

(c) As cell $(3,1)$ has the smallest cost 5 , maximum possible allocation of (6) is made then. Likewise, coming allocation of (1) is made in cell $(3,4)$ and (3) in cell $(3,3)$ as shown.
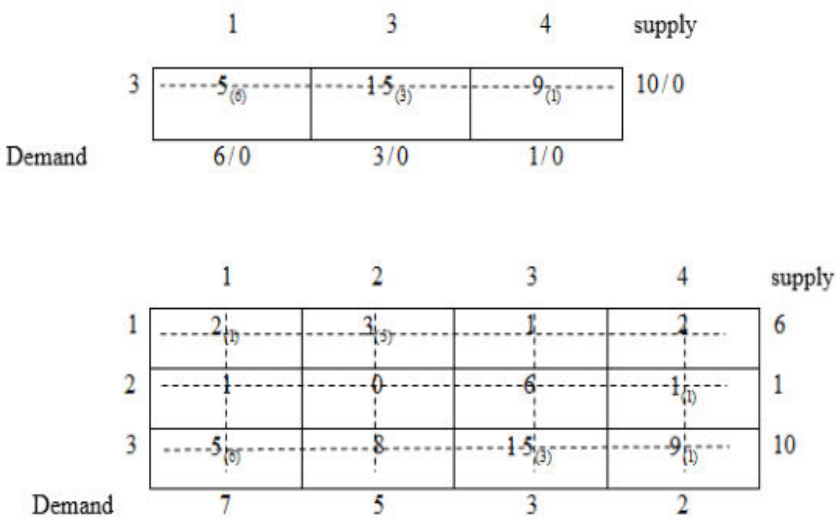

The price of transportation associated with the bellow result is -

$\mathrm{Z}=\mathrm{Tk} .(2 \times 1+3 \times 5+1 \times 1+5 \times 6+15 \times 3+9 \times 1) \times 100$

$=$ Tk. 10200

\section{Let us represent the example graphically}

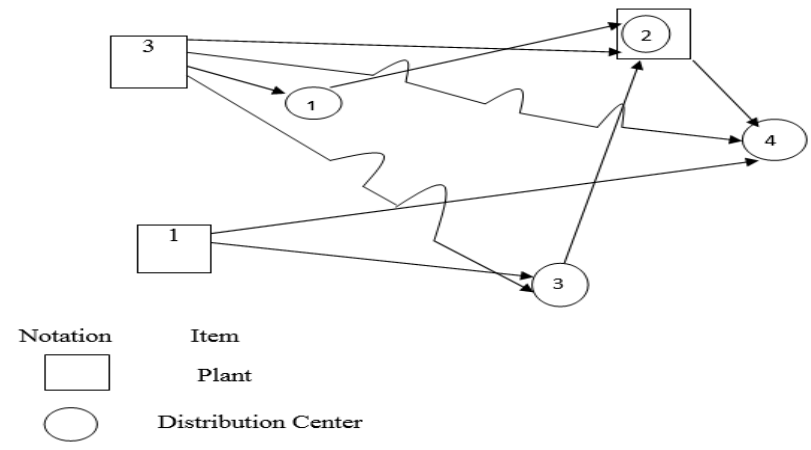

UniversePG I www.universepg.com

\section{CONCLUSION:}

In this paper, we have formulated mathematical programming model of sizeable real life problem and we solved these problems with Mathematica and FORTRAN code. First of all we formulate some real life linear programming problems and solved it graphically by using mathematica. There are some large scale real life problems which cannot be solved graphically but we solved this problem by using simplex technique. We solved some problem by hand calculation and again those problem is solved by FORTRAN program. We see that the result is same. Small problems can be solved with the help of pencil and paper but a large scale real life problem is very difficult to solve by hand calculation. So we can solve this problem easily by using FORTRAN program. Here we formulate two large scale linear programming problems which are solved by using FORTRAN program. On the same way we describe one of the earliest and most useful applications of linear programming techniques has been the formulation and solution of the transportation problem. Computer program is a mighty method for large scale optimization problem, where it can be applied for this we have to model the problem and computer based solution procedure saves our time and labor. Thus the optimization method of linear programming will be useful to the society, business, industries and government if one can formulate the linear programming model of it and required computer program can be developed and used to solve the problem.

\section{ACKNOWLEDGEMENT:}

I would like to express My Teacher and thanks to my friends for their support and advice in completing this paper successfully.

\section{CONFLICTS OF INTEREST:}

This research is contributed by all authors and no potential conflict of interest to publish it.

\section{REFERENCES:}

1) Ali, S.M.E. (2001). A Text Book of Programming in FORTRAN, Beauty Publications, Khulna.

\section{http://www.ajer.org/papers/v4(07)/4-7.pdf}

2) Dantzing, G. B. (1951). Application of the Simplex Method of Transportation Problems, 
Cowles commission Monograph 13, Wiley New York.

https://cowles.yale.edu/sites/default/files/files/pub/ mon/m13-all.pdf

3) Don, E. (2004). Schaum's outline of Theory and Problems of Mathematica, Tata McGraw-Hill Publishing Company Ltd, New Delhi.

4) Gupta, P.K. and Hira, D.S. (2010). Operations Research, S. Chand \& Company Ltd. Publishers, New Delhi.

https://content.kopykitab.com/ebooks/2016/07/806 7/sample/sample_8067.pdf

5) Grewal, B.S. (1998). Higher Engineering Mathematics, Thirty Fourth Edition, Khanna Publication, Delhi.

https://www.academia.edu/38267463/Higher_engi neering_mathematics_bs_grewal

6) Gupta, P. K., Molin, M. (2001). Linear Programming and Theory of games, Thoroughly Revised Edition, Sultan Chand \& Sons Educational Publishers, New Delhi

7) Gupta, R.K. (2006). Krishna's Linear Programming, Twentieth Edition, Krishna Prakashan Media $(P)$ Ltd. Delhi.

8) Hadely, G. (1962). Linear Programming, Addision Wesley, Reading Massachusetts.

https://www.worldcat.org/oclc/1176260260

9) Hitchcock, F.L. (1941). The Distribution of a Product from several sources to numerals locations, Journal of Mathematical Physics. 20(1-4); 224-230

https://onlinelibrary.wiley.com/doi/10.1002/sapm1 941201224

10) Kambo, N. S. (1991). Mathematical Programming Techniques Affiliated East-West Press, New Delhi.

11) Kantorovich, L.V. (1942). On the translocations of masses, Doklady Akad, NaukSSr.

http://www.math.toronto.edu/mccann/assignments/ 477/Kantorovich42.pdf
12) Koopmans, T.C. (1949). Optimum Utilization of the Transportation systems, Econometrica. https://www.jstor.org/stable/1907301

13) Lipschutz, S., Poe, A. (2002). Schaum's outline of Theory and Problems of Programming with FORTRAN, McGraw-Hill lnc, New York. https://inc.kmutt.ac.th/inc161/schaum.pdf

14) Loomba, N.P. (1971). Linear Programming, TMH Edition, Tata McGraw-Hill Publishing Company Ltd, New Delhi.

https://www.worldcat.org/title/linear-programming loclc/502215637?referer=di\&ht=edition

15) Niazai S, Rahimzai AA, Danesh M, and Safi B. (2022). Numerical solution of diffusion equation with caputo time fractional derivatives using finite-difference method with Neumann and Robin boundary conditions, Int. J. Mat. Math. Sci., 4(1), 01-14. https://doi.org/10.34104/ijmms.022.010014

16) Rao, K.C., Mishra, S.L. (2005). Operations Research, Narosa Publishing House Pvt. Ltd, New Delhi.

https://www.bbau.ac.in/dept/UIET/EME-601\%200 peration\%20Research.pdf

17) Reddy, R.N., Ziegler, C. (1990). FORTRAN77 with Applications for Scientists and Engineers, Jaico Publishing House.

https://www.amazon.com/Fortran-77-ApplicationsScientists-Engineers/dp/0314028617

18) Sami HM, Fardous L, and Ruhit DS. (2021). Portfolio optimization in DSE using financial indicators, LSTM \& PyportfolioOpt, Int. J. Mat. Math. Sci., 3(4), 74-84.

https://doi.org/10.34104/ijmms.021.074084

19) Taha, A.H. (2003). Operations Research An Introduction, Seventh Edition, Prentice-Hall of India, Private Limited, New Delhi. http://zalamsyah.staff.unja.ac.id/wp-content/uploa ds/sites/286/2019/11/9-Operations-Research-AnIntroduction-10th-Ed.-Hamdy-A-Taha.pdf

Citation: Hossain S, Aktar S, and Mithy SA. (2022). Solution of large-scale linear programming problem by using computer technique, Int. J. Mat. Math. Sci., 4(1), 15-34. https://doi.org/10.34104/ijmms.022.015034 @ @ @ 